\title{
Common challenges in managing neck and upper limb pain in office workers
}

CPD

Brendan Mouatt, Steven J Kamper

\section{Background \\ Upper limb, cervical and thoracic pain is a common and burdensome problem in Australia. Office workers report high rates of upper body musculoskeletal complaints when compared with workers in other occupations.}

\section{Objective}

This article highlights challenges to providing comprehensive biopsychosocial care for neck, thoracic and related arm pain in office workers, and details the role of active, patientcentred therapies in management.

\section{Discussion}

Cervical, thoracic and upper limb pain is common in office workers. Optimal management comprises a

biopsychosocial patient-centred approach that includes education, reassurance and exercise. Bestevidence treatment of office workers with upper body pain involves an active approach that facilitates self-efficacy and physical activity and reflects a modern understanding of pain.
ACCORDING To the global burden of disease, ${ }^{1}$ neck pain, including pain local to the neck with or without radiating symptoms into the arms, has a point prevalence of $4.9 \%$. Between 1990 and 2010 , the number of years lived with disability due to neck pain increased by $29 \%$ and ranked the fourth highest of all conditions. ${ }^{1}$ Computer- and office-based occupations have the highest incidence of neck and shoulder pain, with almost half of these workers experiencing neck pain in a 12-month period. ${ }^{2}$ Despite the availability of clinical practice guidelines, management of neck and upper body pain in primary care practice varies.

Previous literature has promoted the benefits of a biopsychosocial approach to healthcare. ${ }^{3}$ Despite this, numerous barriers exist for general practitioners (GPs) in providing biopsychosocial care. Drawing on current evidence and clinical experiences in musculoskeletal rehabilitation, this article highlights some of the common challenges in providing biopsychosocial care for the management of upper limb, cervical and thoracic pain in office workers presenting to primary care. This paper assumes that 'red flag' signs and symptoms have been assessed and conservative management is appropriate. Further, this article outlines key management strategies for addressing these barriers to align care with contemporary best evidence.

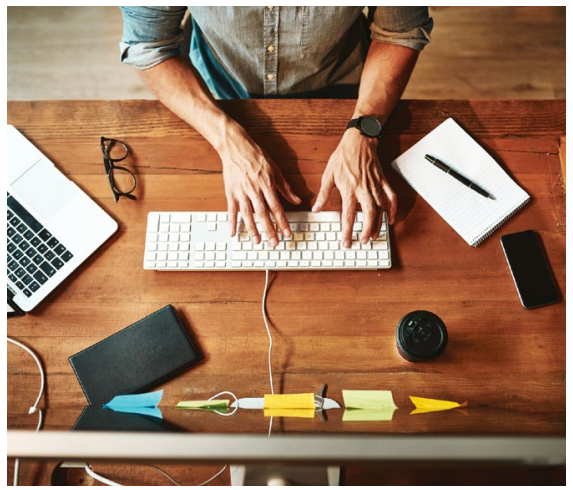

\section{Challenge 1: Providing an accurate diagnosis}

The development of upper limb, cervical and thoracic pain is multifactorial and may involve innervated structures such as zygapophyseal joints, intervertebral discs, bursae, acromioclavicular and glenohumeral joint structures; and soft tissues including rotator cuff muscles and tendons. Because of the low mechanical loads in office occupations, many presentations may not involve structural pathology. The diagnosis of a specific structure is frequently difficult as clinical orthopaedic tests often have high sensitivity and low specificity. ${ }^{4}$ Further, diagnostic imaging studies commonly find structural changes such as intervertebral disc bulges, ${ }^{5}$ rotator cuff tears ${ }^{6}$ and degenerative changes ${ }^{7}$ in asymptomatic populations.

Screening for red flags is an important part of the diagnostic process and should be a routine part of clinical assessment, screening for infection, cancer, arterial insufficiency, cardiac aetiology, acute neurological deficit or fracture. It should also be noted that patients who present with symptoms lasting longer than three months may have a greater central nervous system involvement, which may play a part in the maintenance of pain. Box 1 highlights the broad components that should be incorporated into each clinical interaction. 


\section{Challenge 2: Treating pain}

Historically, pain has been viewed as a direct indicator of tissue pathology or damage. This historical view is challenged by contemporary evidence that shows a poor correlation between structural pathology and pain. ${ }^{5,8}$ Despite this, treatments are often focused on presumed structural, anatomical causes of pain, ${ }^{9}$ resulting in interventions targeting physical, postural, biomechanical and ergonomic mechanisms. This conceptualisation does not align with the International Association for the Study of Pain's definition of pain as 'an unpleasant sensory and emotional experience associated with actual or potential tissue damage, or described in terms of such damage'. ${ }^{10}$ Although the treatment process often does not vary according to structural diagnosis, patients may require education about the nature of pain biology to accept a non-anatomically specific diagnosis.

In a contemporary approach to providing biopsychosocial care for these patients, it is important for practitioners to recognise the biological factors influencing the experience and to also screen for and provide support to address psychological and social influences during a patient's experience. A patient's cognitions and consequent behaviours have been shown to influence prognosis in musculoskeletal pain. ${ }^{1,11,12}$ Because of the time required to adequately address these factors, strategies to effectively assess, educate and provide support efficiently are important.

\section{Challenge 3: Assessing and improving self-efficacy}

Previous literature has found that individuals with positive beliefs regarding their ability to manage pain and achieve functional outcomes (self-efficacy) have lower pain intensity, better physical functioning and lower levels of disability. ${ }^{13}$ A comprehensive subjective interview may flag those with low self-efficacy; however, the use of written outcome measures may provide a time-effective approach to identify individuals with low self-efficacy and fear-avoidance behaviour. The Pain Self-Efficacy
Questionnaire is a 10-item questionnaire that has high reliability and strong construct validity. ${ }^{14}$ The questionnaire is easy to administer and interpret, and it can be used to identify patients who may have low pain self-efficacy. Low scores may indicate the need for further investigation of the patients' beliefs and consequent behaviours with a motivational interviewing approach that provides pain education when appropriate. Psychologist, exercise physiologist or physiotherapist referral may be considered for those presenting with low self-efficacy.

\section{Challenge 4: Applying motivational interviewing techniques to the clinical interaction \\ Motivational interviewing is a patient- centred counselling strategy used to guide a patient to resolve uncertainty}

and engage in positive behavioural change. ${ }^{15}$ This is particularly important when a patient with neck and upper body symptoms presents with low self-efficacy and cognitions that are barriers to engagement in positive behavioural change. Barriers in an office worker

\section{Box 1. Overview of recommendations for the office worker}
1. Screen for red flags
2. Screen for psychosocial factors
3. Use patient-reported outcome measures
4. Conduct a physical examination
5. Address physical activity levels as appropriate
6. Do not refer for imaging unless indicated
7. Encourage early return to work
8. Employ a biopsychosocial patient- centred approach

\begin{tabular}{|c|c|}
\hline Key strategy & Description \\
\hline Create a safe environment & $\begin{array}{l}\text { Provide an environment where the patient feels comfortable } \\
\text { to share details of their situation }\end{array}$ \\
\hline Use open-ended questions & $\begin{array}{l}\text { Avoid using close-ended questions; instead use open-ended } \\
\text { questions that encourage the patient to openly converse }\end{array}$ \\
\hline Empathise & Respond to the patient's perceived challenges with empathy \\
\hline Avoid the 'righting reflex' & $\begin{array}{l}\text { Avoid offering the 'fix' or 'solution' to the problem; instead } \\
\text { help the patient formulate their own potential solutions }\end{array}$ \\
\hline Use affirmations & $\begin{array}{l}\text { Use affirmations of the patient's current progress, } \\
\text { engagement and self-efficacy }\end{array}$ \\
\hline Use simple reflections & Reflect key points to the patient \\
\hline Use complex reflections & $\begin{array}{l}\text { Reflect what the patient has expressed and offer a new } \\
\text { perspective that may allow the patient to reconceptualise } \\
\text { their interpretation }\end{array}$ \\
\hline Reflect discrepancies & $\begin{array}{l}\text { Identify and reflect discrepancies between current } \\
\text { behaviours and goals to the patient }\end{array}$ \\
\hline $\begin{array}{l}\text { Have the patient compare } \\
\text { behavioural outcomes }\end{array}$ & $\begin{array}{l}\text { Ask the patient to compare the potential outcomes of a } \\
\text { behavioural change versus no change }\end{array}$ \\
\hline $\begin{array}{l}\text { Use the 'ask-provide-ask' } \\
\text { technique when educating }\end{array}$ & $\begin{array}{l}\text { Ask the patient what they know about the condition; if } \\
\text { further education is required, the practitioner can express } \\
\text { wanting to share some more information with the patient, } \\
\text { followed by asking for permission to share this information } \\
\text { with them }\end{array}$ \\
\hline Summarise & $\begin{array}{l}\text { Clearly summarise the main goals for the patient; ask the } \\
\text { patient to identify any barriers to achieving their goals and to } \\
\text { verbalise their plan }\end{array}$ \\
\hline
\end{tabular}


population may include poor engagement with active therapies, fear that they are damaged or concern that their condition will deteriorate. ${ }^{16}$ Key skills that a GP can adopt in a consultation can be seen in Table 1, developed from Levensky et al and McCarley. ${ }^{17,18}$

\section{Challenge 5: Delivering pain education}

Pain education is known to be effective for patients with persistent musculoskeletal pain. ${ }^{19}$ For patients who present with high fear avoidance, low self-efficacy, signs of catastrophising or poor pain beliefs, pain education may enable reconceptualisation of several misconceptions that are common in society (Table 2). Education may be delivered verbally or via other strategies, such as workbooks, drawings and multimedia. ${ }^{20}$ It is important to identify these unhelpful misconceptions and reconcile them during the initial and subsequent consultations.

\section{Challenge 6: Prescribing active approaches to pain}

\section{Exercise and physical activity}

As for the general population, achieving adequate physical activity is beneficial for those with pain, ${ }^{21}$ including those with neck pain. ${ }^{22}$ For persistent neck pain, evidence supports upper body resistance training, muscular endurance training and stretching. ${ }^{23}$ With regard to general musculoskeletal pain, supervised exercise prescription may be beneficial. Ensuring safety and adherence to recommendations may require exploration of the beliefs, behaviours and expectations of the patient, followed by addressing these as appropriate. ${ }^{16,24}$
It should be noted that although many find analgesia in active therapy, people with persistent pain may have unpredictable responses, with symptom intensity varying, especially initially. ${ }^{25}$ Despite varying responses to exercise, benefits can be seen from exercise regardless of analgesia, such as increases in self-efficacy and decreases in fear avoidance. ${ }^{16,26}$ For this reason, an approach that facilitates graded exposure to physical activity is advised and may require supervision from a suitably experienced exercise physiologist or physiotherapist.

\section{Type of exercise}

Evidence suggests that resistance exercises are effective in decreasing pain and improving function in office workers. ${ }^{27}$ High-load upper trapezius resistance training for 30 minutes, two days per week, for five weeks, led to

\section{Table 2. Key target concepts and example explanations (adapted with permission from Butler and Moseley) ${ }^{20}$}

\begin{tabular}{ll} 
Target concept & Explanation \\
\hline Pain and tissue damage rarely relate & The amount of pain you feel is rarely associated with the extent of tissue damage. We can \\
& have serious injuries with minimal pain. Alternatively, we can have pain without an injury. \\
& With exercise we can be sore but safe; pain does not always mean there is damage.
\end{tabular}

There are danger sensors in the body, not pain sensors

Pain depends on context
Our nervous system is a danger alarm system. We have danger sensors throughout the body. There are no pain sensors or pathways.

Many factors can influence pain, such as your previous experiences; beliefs; your location; what is happening in your body; what you see, hear, touch and taste; the people you are with and the places you go.
Pain depends on the perceived balance of danger and safety

Pain is one of many protective outputs

We are bioplastic

There are many active treatment strategies

Pain is always real and unique to us

Some pain during exercise may be beneficial
Our brain evaluates all the credible evidence of danger and safety to our body including information from danger sensors and contextual information. If we perceive more danger, then we are more likely to have a protective response such as pain. If we perceive more safety, we will likely have less or no pain.

Pain is not the only protection we have. Our immune, autonomic, endocrine, cognitive, emotional and movement responses can also be protective, at least in the short term. We may even have symptoms such as stiffness and fatigue to protect us.

The protective systems that lead to pain and other outputs can be turned up; likewise, this protective system is always changing and can also be turned down with a reduction of threat.

Active treatment strategies are nearly always preferred to passive strategies. Examples include graded exercise, knowledge acquisition, dietary and sleep modification, socialising, contact with nature, and anything enjoyable in moderation.

Pain is always real. The experience of pain differs between people and is influenced by our own unique factors (as outlined above in 'Pain depends on context'). Pain is never 'just all in your head'; it is a bodily construction, masterminded by your brain in response to threat.

Sometimes you can be sore but safe to move (as outlined above in 'Pain and tissue damage rarely relate'). An appropriate level of pain is what you can tolerate during movement, but also what you can tolerate after exercise. 
improvements in pain and disability. ${ }^{27}$ Similarly, clinically significant results were seen in interventions that exposed symptomatic workers to as little as two minutes of strengthening exercises per day, five days per week, for 10 weeks. ${ }^{28}$ Findings suggest that the specific training protocol may not be as important as advising the patient to regularly perform loaded activity. Nevertheless, identifying the optimal dose of exercise for this population is a research priority.

Effectiveness of exercise appears to be similar regardless of whether the exercises are painful to complete. ${ }^{29}$ Furthermore, some pain may be beneficial in decreasing pain-related fear and reassuring patients that pain need not be a barrier to movement..$^{29}$ However, pain education and reassurance should be provided when exercise that evokes pain is prescribed. ${ }^{24,30}$

Exercise that an individual enjoys is more likely to be adhered to and prioritised. However, for those without access to resistance equipment, bodyweight exercise or using household items may be a viable alternative. Further, increasing general physical activity regardless of the inclusion of specific upper body exercises may be enough for many patients, thus financial concerns need not be a barrier to recovery. Exercise guidance and dosage examples are shown in Table 3.

\section{Workplace exercise interventions}

There is reason to believe that workplace exercise interventions that target the upper body may be effective in improving outcomes in workers with neck and shoulder symptoms. ${ }^{31,32}$ It is not clear if workplace interventions are more effective than home-based or supervised exercise. General fitness interventions in the workplace also have small effects in improving outcomes for symptomatic office workers but less analgesic benefit than upper body strengthening exercises. ${ }^{33}$

\section{Referral for active therapy}

Referral to an allied health professional (eg Accredited Exercise Physiologist) may

Table 3. Exercise recommendations and guidelines ${ }^{39}$

\begin{tabular}{|c|c|}
\hline Population & Dosage \\
\hline \multirow[t]{5}{*}{$\begin{array}{l}\text { Office workers } \\
\text { with pain }\end{array}$} & $\begin{array}{l}\text { General upper body resistance-based exercises performed regular } \\
\text { throughout the week while symptoms persist; for example: }\end{array}$ \\
\hline & $\begin{array}{l}\text { - two minutes per day of upper body resistance-based exercise } \\
\text { (resistance bands or weighted upper body exercises), five days per }\end{array}$ \\
\hline & $\begin{array}{l}\text { - } 30 \text { minutes per day of heavy resistance exercises (weighted shr } \\
\text { pushing, pulling exercises), two days per week }\end{array}$ \\
\hline & $\begin{array}{l}\text { Advice to progressively increase physical activity in line with the } \\
\text { general exercise guidelines for healthy populations (below); this ca } \\
\text { include bodyweight-based exercise }\end{array}$ \\
\hline & $\begin{array}{l}\text { Note: Exercises should be within the patient's tolerances and } \\
\text { gradually increase resistance, repetitions and sets. }\end{array}$ \\
\hline \multirow[t]{2}{*}{ Healthy population } & $\begin{array}{l}150 \text { minutes per week of moderate-to-vigorous-intensity aerobic } \\
\text { exercise or } 75 \text { minutes of high-intensity exercise per week* } \\
+\end{array}$ \\
\hline & $\begin{array}{l}\text { Two resistance training sessions per week, training all major } \\
\text { muscle groups }\end{array}$ \\
\hline
\end{tabular}

Overweight, comorbid 300 minutes per week of moderate-to-vigorous-intensity exercise or metabolic conditions 150 minutes of high-intensity exercise per week*

$+$

Two resistance training sessions per week, training all major muscle groups

${ }^{*}$ A combination of high intensity and moderate-to-vigorous intensity exercise can be considered. be indicated for patients with barriers to exercise. Interventions should address fear avoidance and unhelpful pain beliefs and improve exercise self-efficacy within a biopsychosocial framework. ${ }^{24}$ Referral for supervised exercise may be appropriate for individuals reporting symptoms persisting longer than three months. ${ }^{31,34}$ Consideration of a multidisciplinary approach (including physiotherapy, psychology, dietetics, etc) may be considered as this has empirical support for people with low back pain. ${ }^{35}$

\section{Manual and passive therapies}

A 2015 systematic review and meta-analysis found weak evidence supporting the use of cervical or thoracic manipulation or mobilisation for temporary neck pain relief, ${ }^{36}$ but manual therapy likely provides no extra benefit at short- or long-term follow-up beyond exercise therapy alone. ${ }^{37}$ Such passive therapies may be considered when transitioning patients with strong passive therapy expectations to active strategies. Guidelines recommend that manual therapy be used only as an adjunct to other active therapies. ${ }^{38}$

\section{Conclusion}

Cervical, thoracic and upper limb pain is common in office workers. Optimal management comprises a biopsychosocial, patient-centred approach that includes education, reassurance and exercise. Best-evidence treatment for office workers with upper body pain involves an active approach that facilitates self-efficacy and reflects a modern understanding of pain.

\section{Key points}

- Interventions that promote activity are helpful to reduce upper body symptoms of office workers.

- Improvements in pain and function can be seen with modest increases in physical activity.

- Pain education in conjunction with a motivational interviewing approach may be helpful to improve patient engagement in active therapies and improving self-efficacy. 


\section{Authors}

Brendan Mouatt MClinExPhys, higher degree by research masters candidate and Accredited Exercise Physiologist, School of Health Sciences, University of South Australia, SA. brendan@tkex.org

Steven J Kamper PhD, Associate Professor, Centre for Pain, Health and Lifestyle, NSW; Associate Professor, School of Public Health, University of Sydney, NSW

Competing interests: None.

Funding: None.

Provenance and peer review: Commissioned, externally peer reviewed.

\section{References}

1. Hoy D, March L, Woolf A, et al. The global burden of neck pain: Estimates from the global burden of disease 2010 study. Ann Rheum Dis 2014;73(7):1309-15. doi: 10.1136/ annrheumdis-2013-204431.

2. Cagnie B, Danneels L, Van Tiggelen D, De Loose V, Cambier D. Individual and work related risk factors for neck pain among office workers: A cross sectional study. Eur Spine J 2007;16(5):679-86. doi: 10.1007/s00586-0060269-7.

3. Havelka M, Despot Lučanin JD, Lučanin D. Biopsychosocial model - The integrated approach to health and disease. Coll Antropol 2009;33(1):303-10.

4. Hegedus EJ, Goode AP, Cook CE, et al. Which physical examination tests provide clinicians with the most value when examining the shoulder? Update of a systematic review with meta-analysis of individual tests. $\mathrm{Br} J$ Sports Med 2012;46(14):964-78. doi: 10.1136/ bjsports-2012-091066.

5. Nakashima $H$, Yukawa $Y$, Suda $K$, Yamagata $M$ Ueta T, Kato F. Abnormal findings on magnetic resonance images of the cervical spines in 1211 asymptomatic subjects. Spine (Phila Pa 1976) 2015;40(6):392-98. doi: 10.1097/ BRS.0000000000000775.

6. Minagawa $\mathrm{H}$, Yamamoto $\mathrm{N}$, Abe $\mathrm{H}$, et al. Prevalence of symptomatic and asymptomatic rotator cuff tears in the general population: From mass-screening in one village. J Orthop 2013;10(1):8-12. doi: 10.1016/j.jor.2013.01.008.

7. Shubin Stein BE, Ahmad CS, Pfaff $\mathrm{CH}$, Bigliani LU, Levine WN. A comparison of magnetic resonance imaging findings of the acromioclavicular joint in symptomatic versus asymptomatic patients. J Shoulder Elbow Surg 2006;15(1):56-59. doi: 10.1016/j.jse.2005.05.013.

8. Lederman E. The fall of the posturalstructural-biomechanical model in manual and physical therapies: Exemplified by lower back pain. J Bodyw Mov Ther 2011;15(2):131-38. doi: 10.1016/j.jbmt.2011.01.011.

9. Siddall PJ, Cousins MJ. Persistent pain as a disease entity: Implications for clinical management. Anesth Analg 2004;99(2):510-20. doi: 10.1213/01.ANE.0000133383.17666.3A.

10. Pain terms: A list with definitions and notes on usage. Recommended by the IASP Subcommittee on Taxonomy. Pain 1979;6(3):249.

11. Cohen SP. Epidemiology, diagnosis, and treatment of neck pain. Mayo Clin Proc 2015;90(2):284-99. doi: 10.1016/j.mayocp.2014.09.008

12. Vos CJ, Verhagen AP, Passchier J, Koes BW. Clinical course and prognostic factors in acute neck pain: An inception cohort study in general practice. Pain Med 2008;9(5):572-80. doi: 10.1111/j.1526-4637.2008.00456.x.
13. Martinez-Calderon J, Zamora-Campos C, Navarro-Ledesma S, Luque-Suarez A. The role of self-efficacy on the prognosis of chronic musculoskeletal pain: A systematic review. J Pain 2018;19(1):10-34. doi: 10.1016/j.jpain.2017.08.008.

14. Nicholas MK. The pain self-efficacy questionnaire: Taking pain into account Eur J Pain 2007;11(2):153-63. doi: 10.1016/j. ejpain.2005.12.008.

15. Miller WR, Rose GS. Toward a theory of motivational interviewing. Am Psychol 2009;64(6):527-37. doi: 10.1037/a0016830.

16. Kroll HR. Exercise therapy for chronic pain. Phys Med Rehabil Clin N Am 2015;26(2):263-81. doi: 10.1016/j.pmr.2014.12.007.

17. Levensky ER, Forcehimes A, O'Donohue WT, Beitz K. Motivational interviewing: An evidencebased approach to counseling helps patients follow treatment recommendations. Am J Nurs 2007:107(10):50-58, doi: 10.1097/01. NAJ.0000292202.06571.24

18. McCarley P. Patient empowerment and motivational interviewing: Engaging patients to self-manage their own care. Nephrol Nurs J 2009;36(4):409-13.

19. Louw A, Diener I, Butler DS, Puentedura EJ. The effect of neuroscience education on pain, disability, anxiety, and stress in chronic musculoskeletal pain. Arch Phys Med Rehabil 2011;92(12):2041-56. doi: 10.1016/j.apmr.2011.07.198.

20. Butler DS, Moseley GL. Explain pain supercharged. Adelaide City West, SA: NOI Group Publications, 2017

21. Meeus M, Nijs J, Van Wilgen P, Noten $S$ Goubert D, Huijnen I. Moving on to movement in patients with chronic joint pain. Pain Clinical Updates 2016;24(1):1-8.

22. Hurwitz EL, Carragee EJ, van der Velde G, et al. Treatment of neck pain: Noninvasive interventions: Results of the bone and joint decade 2000-2010 task force on neck pain and its associated disorders. J Manipulative Physiol Ther 2009;32(Suppl 2):S141-S75. doi: 10.1016/j. jmpt.2008.11.017.

23. Gross A, Paquin JP, Dupont $G$, et al. Exercises fo mechanical neck disorders: A Cochrane review update. Man Ther 2016;24:25-45. doi: 10.1016/j. math.2016.04.005

24. Booth J, Moseley GL, Schiltenwolf M, Cashin A Davies M, Hübscher M. Exercise for chronic musculoskeletal pain: A biopsychosocial approach. Musculoskeletal Care 2017;15(4):413-21. doi: 10.1002/msc.1191.

25. Naugle KM, Fillingim RB, Riley JL 3rd. A metaanalytic review of the hypoalgesic effects of exercise. J Pain 2012;13(12):1139-50. doi: 10.1016/j. jpain.2012.09.006.

26. Kernan T, Rainville J. Observed outcomes associated with a quota-based exercise approach on measures of kinesiophobia in patients with chronic low back pain. J Orthop Sports Phys Ther 2007;37(11):679-87. doi: 10.2519/jospt.2007.2480.

27. Heredia-Rizo AM, Petersen KK, Madeleine $P$, Arendt-Nielsen L. Clinical outcomes and central pain mechanisms are improved after upper trapezius eccentric training in female computer users with chronic neck/shoulder pain. Clin J Pain 2019;35(1):65-76. doi: 10.1097/ AJP.0000000000000656.

28. Andersen LL, Saervoll CA, Mortensen OS, Poulsen OM, Hannerz H, Zebis MK. Effectiveness of small daily amounts of progressive resistance training for frequent neck/shoulder pain: Randomised controlled trial. Pain 2011;152(2):440-46. doi: 10.1016/j. pain.2010.11.016
29. Smith BE, Hendrick P, Smith TO, et al. Should exercises be painful in the management of chronic musculoskeletal pain? A systematic review and meta-analysis. Br J Sports Med 2017;51(23):1679-87. doi: 10.1136/ bjsports-2016-097383.

30. Hopman K, Krahe L, Lukersmith S, McColl A, Vine K. Clinical practice guidelines for the management of rotator cuff syndrome in the workplace. Port Macquarie, NSW: The University of New South Wales; 2013.

31. Bussieres AE, Stewart G, Al-Zoubi F, et al. The treatment of neck pain-associated disorders and whiplash-associated disorders: A clinical practice guideline. J Manipulative Physiol Ther 2016;39(8):523-64.e27. doi: 10.1016/j. jmpt.2016.08.007.

32. Chen $X$, Coombes BK, Sjøgaard G, Jun D, O'Leary S, Johnston V. Workplace-based interventions for neck pain in office workers: Systematic review and meta-analysis. Phys The 2018;98(1):40-62. doi: 10.1093/ptj/pzx101.

33. Blangsted AK, Sogaard K, Hansen EA, Hannerz H, Sjøgaard G. One-year randomized controlled trial with different physical-activity programs to reduce musculoskeletal symptoms in the neck and shoulders among office workers. Scand J Work Environ Health 2008;34(1):55-65. doi: 10.5271/ sjweh.1192.

34. Côté P, Wong JJ, Sutton D, et al. Management of neck pain and associated disorders: A clinical practice guideline from the Ontario Protocol for Traffic Injury Management (OPTIMa) Collaboration. Eur Spine J 2016;25(7):2000-22. doi: 10.1007/s00586-016-4467-7.

35. Kamper SJ, Apeldoorn A, Chiarotto A, et al. Multidisciplinary biopsychosocial rehabilitation for chronic low back pain: Cochrane systematic review and meta-analysis. BMJ 2015;350:h444 doi: 10.1136/bmj.h444.

36. Gross A, Langevin P, Burnie SJ, et al. Manipulation and mobilisation for neck pain contrasted against an inactive control or another active treatment. Cochrane Database Syst Rev 2015;(9):CD004249. doi: 10.1002/14651858.CD004249.pub4.

37. Fredin $\mathrm{K}$, Lorås $\mathrm{H}$. Manual therapy, exercise therapy or combined treatment in the management of adult neck pain - A systematic review and meta-analysis. Musculoskelet Sci Pract 2017;31:62-71. doi: 10.1016/j.msksp.2017.07.005.

38. Lin I, Wiles L, Waller R, et al. What does best practice care for musculoskeletal pain look like? Eleven consistent recommendations from high-quality clinical practice guidelines: Systematic review. Br J Sports Med 2019:bjsports-2018-099878. doi: 10.1136/ bjsports-2018-099878.

39. Garber CE, Blissmer B, Deschenes MR, et al. American College of Sports Medicine position stand. Quantity and quality of exercise for developing and maintaining cardiorespiratory, musculoskeletal, and neuromotor fitness in apparently healthy adults: Guidance for prescribing exercise. Med Sci Sports Exerc 2011;43(7):1334-59. doi: 10.1249/ MSS.0b013e318213fefb.

correspondence ajgp@racgp.org.au 